\title{
Media and Generations in Portugal
}

\author{
Jorge Vieira
}

Center for Research and Studies in Sociology (CIES-IUL), Department of Sociology, University Institute of Lisbon (ISCTE-IUL), 1600-077 Lisboa, Portugal; jorge_vieira@iscte-iul.pt

Received: 1 June 2018; Accepted: 28 July 2018; Published: 2 August 2018

\begin{abstract}
Many discourses link media with generations, ascribing particular appetence for the use of new media to youth, in contrast with older generations. This article aims to give an account of the empirical regularities but also differences found in a longitudinal quantitative analysis of Internet users, uses, and media preferences among different Portuguese age cohorts. Making use of questionnaire surveys with representative samples, the importance of generational belongings in structuring different types of relationships with media is demonstrated, as youngsters seem to prefer new media. However, this variable does not hold in itself complete explanatory power. The importance of formal education, besides other sociographic variables, is clear, indicating the existence of social disparities within age cohorts, with repercussions on the mediated access to resources and opportunities. The diversity and inequalities found through the statistical analysis help to combat the rhetoric of a supposedly innate, all-encompassing digital nativity. By adopting a social constructivist approach, with a more holistic scope, this article also aims to reconstruct part of the complexity and multidimensionality of the relationship between and within Portuguese generations with media, thereby deconstructing more essentialist and homogenising notions of youth and generations.
\end{abstract}

Keywords: generations; media; digital divide

\section{Introduction}

\subsection{Aims, Research Questions, and Relevance}

We constantly see the category "generations" being used as a way of understanding and describing the world—generationalism [1] —and, in parallel, a re-emergence of its use in youth studies [2].

It has also been used to understand the relationship of people with media in a contemporary world characterized by the increasing importance of mediation [3] within a process of deep mediatization [4] that, dialectically, influences society. More than ever, media pervades everyday life [5] and are part of the "texture of experience" [6] (p. 2), amounting to a crucial force of symbolic power [7], for much of the social construction of reality is now mediated [4]. Therefore, media is a crucial field that must be studied if we wish to better understand contemporary societies.

Drawing on the sociological importance of generations, this article aims to provide an account of the empirical regularities, but also differences, found in a longitudinal quantitative analysis of Portuguese Internet uses and media preferences among different age cohorts-which can be defined as "those persons born in the same time interval and aging together (... )" [8] (p. 844), "who experienced the same event within the same time interval" [8] (p. 845).

Approaching the problem from a multidimensional perspective rooted in the Portuguese context-a country that ranks 16th out of the $28 \mathrm{EU}$ member states in "The Digital Economy and Society 
Index" (DESI $\left.{ }^{1}\right) 2018$ edition, therefore belonging to the medium-performing cluster of countries - the following main research question was formulated:

RQ: Is there, in the Portuguese context, anything particular about the relationship of youth with media?

Alongside which, a few subsidiary research questions were formulated:

SRQ 1.1: Are there different patterns of Internet use in Portugal? SRQ 1.2: If so, what are they like? Is Portuguese youth more predisposed to new media use and online activities than the older generations? SRQ 1.3: If it is, can we relate these differences to age cohorts?

SRQ 2.1: Do different age cohorts prefer different media-youth favouring new media vs. elderly generations favouring mass media? SRQ 2.2: If this is the case, can these differences be explained solely on the basis of age cohorts?

\subsection{Generations}

To discuss generations by overcoming a more naturalistic definition, one that sees generations as simply succeeding one another in linear order, we must turn to the seminal work of Karl Mannheim [9]. Mannheim proposed a historical, culturalist view of generations, stating that age cohorts on their own are not sufficient to shape a unified sense of generational belonging within coevals. He thus unfolded generations into a tripartite typology: a sense of collective generational identity is formed not merely out of being born at the same historical time and place (generation as location - Generationslagerung), but by synchronically experiencing crucial, shared historical events and societal processes, at the same biographical stage (generation as actuality-Generationszusammenhang). Hence, generations are not reducible to coevals. Generation as an actuality only emerges when a worldview, a collective memory, and self-consciousness are shared but, even within this age cohort, social differentiation will be found - the so-called generation units (Generationseinheiten), or social generations, as refined by Pilcher [10] and Aboim and Vasconcelos [11], who have shed light on this multidimensional approach to generations. This notion of generation unit intends to move beyond a reductionist, homogeneous view of age cohorts by fostering a sociological view instead.

Many have followed and proposed refinements of Mannheim's seminal contributions [10-15]. Some have combined Manheim's legacy with the contributions of Bourdieu [13,16,17]. Based on sociological theory and drawing mainly on Bourdieu, a generation can be defined as "a cohort of persons passing through time that come to share a common habitus, hexis and culture, a function of which is to provide them with a collective memory that serves to integrate the cohort over a finite period of time" [13] (p. 93). A generation must then have a kind of self-reference and a "we-sense" [14] (p. 258).

\subsection{Media and Generations}

The academic discourse relating generations and media is not new [18]. One of the most strongly used terms in contemporary discourse on media and generations has been that of "digital natives", coined by Marc Prensky $[19,20]$. However, other concepts attempting to refer to the relationship between generations and media have been crafted. To name a few: Tapscott [21] employed the term "net generation" for all those born between 1977 and 1997, Rheingold [22] coined the term "generation $t_{x t}$ ", associating it with the use of text messages, Feixa wrote about the "generation@" [23] and later on the "\#generation" [24], Huang [25] of the "social media generation" and Taipale of "first" and "second digital generation" [26], Sackmann and Winkler, based on the idea of technology generations, as "groups of birth cohorts whose conjunctive experience with technology is differentiated by social change" [27] (p. 493), have found empirical evidences of a technological associated cohort influence with the emergence of an "internet generation" (those born after 1980).

1 https://ec.europa.eu/digital-single-market/en/desi. 


\subsection{Media, Youth, and the Social}

At an almost similar pace to this lexical fruitfulness and sometimes simplistic abuse by media discourses (often transforming complex and multidimensional concepts into shallow buzzwords) contributions have been made towards the critical deconstruction of the rhetoric present in some of the epistemological foundations of a supposedly "digital global generation" composed of "digital natives" [28-34]. These criticisms call for a more refined and multidimensional view that does not conceal internal variations existing within this age cohort, situating it instead within multiple contexts of existence. Special vigilance against the danger of expressions like "digital generation" is stressed $[35,36]$, as well as against other kinds of essentialist notions, abusive, labels, and forced dichotomies between generations, based solely on the year of birth and apparently defined by technology alone.

It is important not to forget that media and youth are not monolithic categories [37]—in fact, youth and its meanings are increasingly elastic [38] (p. 6). Reference to Bourdieu's classical text_- Youth is just a word" [39] - is already an academic social regularity in the sociological approach to youth. It is typically employed to promote an understanding of youth that is not only biological but that views youth as a socially constructed category-since the divisions between ages are arbitrary. It is a socially (re)constructed and contingent notion that depends on the historical, cultural, and social context in which it is rooted. As such, the prior delineation of youth in an age cohort is artificial and does not allow to encapsulate the juvenile condition. This condition is typically marked by a transitional phase in the life course, between adolescence and adulthood, characterised by dependence, but also by the construction of autonomy. At this articulated juncture, there is an enormous diversity of individual biographies and social contexts of existence.

Buckingham [40] supports that the repercussions of technology are not rigid, affecting all social agents, regardless of their generation. The impacts of media will depend more on the conditions of their use than on generational belonging. These individual contexts and life courses, id est "a sequence of socially defined events and roles that the individual enacts over time" [41] (p. 22) are variable and unequal, even within a specific age cohort. Buckingham also criticises the dualistic narrative of natives versus emigrants, and therefore, an exotic and essentialist take on youth, which can inflate the already distorted view of a profound and uncommunicative generational divide. Moreover, continuity, intrinsic of social change, is still often neglected and absolute power is conferred to media and technology [36,42]. In fact, a historical reading shows that many of the apparently radical innovations are, in fact, reconfigurations through new modalities [43].

Therefore, it is necessary to reject views of media and society imbued with technological determinism [44]. As Wajcman [45] advises, it is important to refute the grounds of this more essentialist view, realising that any technological system is never merely technical, but rather the reflection of a technical dimension, which is also political, economic, cultural, and organisational. Selwin [46] even appeals for academics to critically withdraw from this sociocentric view on youth and new media, stressing the need to "make the familiar strange"-here paraphrasing Mills' classic [47]. To that effect, it is important not to forget the social component of digital technologies and to recapture social theory for a sociological mode of reasoning that avoids, among others, on the one hand, the danger of technological determinism and Manichaean cause-effect thinking; but also, on the other hand, the opposite intellectual trap of anti-essentialism or sociologism. In that sense, it is important to adopt anti-deterministic theories that defend the flexibility both of technology and of social interpretations. Namely, those under the terminological umbrella proposed by MacKenzie and Wajcman [48] - the "social shaping of technology" (SST) [49]—from where the line of the "social construction of technology" (SCOT) is derived [50,51], as well as theories of domestication [52-56]. Both proposals, epistemologically rooted in social constructivism, make it possible to understand the relationship between technology and society in dynamic terms, defending that the two are mutually shaped in a dialectical way. In other words, technologies and practices of users are co-constructed [57]. Therefore, the relationships between media and society are dynamic and dialectical, and the process of information and communications 
technologies (ICT) adoption and domestication is not homogeneous in all age cohorts but characterised by social disparities instead.

\subsection{Digital Divide}

Focusing on these differentiations and social inequalities, the problem of the digital divide emerged in academic and political discourses in the 1990s [58]. In that still, embryonic stage of Internet dissemination characterised by relatively unsophisticated platforms and uses, academic and political agents analysed the problem mainly in infrastructural terms [59] (p. 193), and particularly concerned with issues related to the inequalities existing in patterns of access to ICTs $[54,60]$.

The passage of time-both in social reality and in technology, as well as in the ways of thinking this relation-brought the term "second-level digital divide" [61] into academic discourse. This term calls for the need of a more sophisticated and multidimensional analysis [62], one that pays due attention to the differences in activities and uses $[63,64]$, as well as to different levels of media literacy. Essentially, with the change in nomenclature, there was a shift from the dichotomous digital divide to a more nuanced digital spectrum $[65,66]$ and an interest in digital inequality [67], id est in the digital and networked disparities resulting from (and leading to) different social contexts and the unequal access and distribution of resources.

More recently, with increasing access to ICTs and the consolidation of research, some authors have started to refer to a "third-level digital divide" [68], linked to individuals' capacity to effectively capitalise the potential of new media and their tangible outcomes [69,70]. Since Internet use may, or may not, be used as a tool for capital accumulation [71], the central question now is: who benefits from the use of ICTs and how? This view establishes the link between online and offline by calling for an epistemological approach that regards these two dimensions as being interdependent and superimposed [72-75]—debunking the myth of the cyberspace [73]. Likewise, it thereby rejects technological determinism, attempting to understand how new media are embedded in the social fabric, and consequently, are also socially co-shaped.

\subsection{Youth and New Media Studies}

An empirical observation of the disparate relationships social agents establish with media helps to deconstruct discourses on the homogenising power of media and to overthrow any deterministic, linear and rigid conception of society and generations. In fact, and focusing on young people, there is countless empirical evidence reflecting, on the one hand, their unequal access to ICTs, and, on the other hand, their varied relationships with media [31].

These studies empirically show how generational belonging has served to predict the use of new media over the years and across different national contexts, with youth being faster in the adoption of ICTs [75].

According to Mannheim's generational reasoning, being part of the same age cohort implies the location and exposure to specific historical events, particular life chances and, at the same time, the experience of a particular media environment-defined as "the entire body of available media at any given time" [76] (p. 3). Besides this affinity on a more material and infrastructural level, media can participate at the symbolic level in this process of mediating forms of collective memory, while also promoting generational identities $[18,77]$. This is even more relevant, especially with "fresh contact" amid the formative stages of the life course, such as the years of late adolescence and youth $[9,78]$. Therefore, there is theoretical basis supporting the fact that childhood and adolescence are fundamental stages at the beginning of media socialisation and media biographies [77], which can shape future patterns of media domestication and literacy [18], as well as promote media nostalgia [79,80].

These studies tend to recognise greater appetence on the part of younger people, nevertheless, this does not happen in an all-encompassing manner that allows saying there is a unitary digital generation. It is not only technologies that promote and accelerate those differences in practices and representations in a direct, unilateral way. Therefore, it is necessary to adopt a critical perspective 
towards homogeneous categorisations of merely generational or age cohorts and be vigilant to contexts of use (and non-use) in order to better understand practices and their circumstances [54]. Especially because most of the research suggests that young people are interested in, and motivated for, the use of ICTs, more because of what they can access and do by using them than because of technology in itself [36] (p. 9).

Additionally, the use of new media does not, on its own, miraculously instil in its users neither digital erudition nor a conscious, critical and sophisticated media use. Hargittai [81] portrays different levels of literacy and autonomy in the use of new media through the so-called Internet generation-from digital natives to "digital naives". In other words, uses among young people are not always as sophisticated and rich as is commonly believed, nor are these agents as techno savvy [82] as some less attentive, homogenising interpretations portrait them. In this fashion, even among young people with access to ICTs, gradations of digital inclusion/exclusion were found; not all were capable, to the same extent, of a selective, filtered appropriation, guided by the achievement of individual and collective goals. This means they reached different positions on the ladder of opportunities [83]. What qualifies a basic, autonomous user in the use of media is to be found in a complex network of variables, which includes, for example, the experience and scope of the use, but also attributes like age, gender, and education [30] (p. 506), as well as the person's stage in the life course. Recently a new body of knowledge tries precisely to promote a generational perspective to social change [84] and address the importance of media in the formation of generational belonging [85] alongside the role of individual life course regarding media adoption and use [86-88].

\section{Materials and Methods}

The data analysed here stem from the collection of data lead by the Portuguese Observatory of Communication (OberCom) and Centre for Research and Studies in Sociology-CIES-IUL (Centro de Investigação e Estudos de Sociologia), through the wave of surveys "Sociedade em Rede" (Network Society) ${ }^{2}$, to which the 2015 questionnaire "ERC—Públicos e Consumos de Média" (ERC-Media Audiences and Consumption) $)^{3}$ from the Portuguese Media Regulatory Authority (ERC-Entidade Reguladora para a Comunicação Social) was added.

They are face-to-face questionnaire surveys representative of Portuguese subjects living in mainland Portugal aged 15 or more. The analysis combined the use of univariate and bivariate descriptive statistics, as well as multivariate methods of analysis carried out with the SPSS program.

Using the theoretical insights presented in the introduction, data was analysed in order to find the importance of age of birth in shaping different domestications and preferences regarding the media, understanding that the concept of generation is problematic, as it simplifies multidimensional features. Following Mannheim, one should be vigilant in order to not take the risk to conflate generation as location as generation as actuality or unity, knowing that the family of three time based, historicising concepts of generation, cohort and life course are many times, erroneously, conflated and used interchangeably [89]. Nevertheless, in order to operationalize empirically the research question age cohorts were drawn, knowing that in a generational analysis the difficult question is inevitably were to draw sharp cuts between age cohorts [84-87].

\section{Results}

\subsection{Growth in the Number of Internet Users and Digital Divide}

First of all, considering the rate of Portuguese Internet users, considerable growth was witnessed in Portugal (Figure 1). Whereas in 2003 Internet users accounted for less than a third (29\%) of

\footnotetext{
Data collected in 2003, 2006, 2008, 2010, 2011, and 2013.

Fieldwork conducted by Intercampus and GfK in continental Portugal.
} 
the population above 15 years, in 2015 that number had risen to nearly two thirds (60.5\%)-in the intervening years the rate was, respectively: $33.8 \%$ in $2006 ; 40.7 \%$ in $2008 ; 44.5 \%$ in $2010 ; 49.2 \%$ in 2011 ; and above the half threshold (55.2\%) in 2013.

Focusing on the $39.5 \%$ who claimed in 2015 to be non-users, $7.2 \%$ stated they had used before. That is, in overall terms, $2.8 \%$ abandoned their use and can be considered dropouts. Among the reasons for non-use and digital disengagement [90] nearly half (48.3\%) of those who stopped using indicate price, but motivational elements are also important: $27.6 \%$ point to a lack of interest and $24.1 \%$ to lack of time.

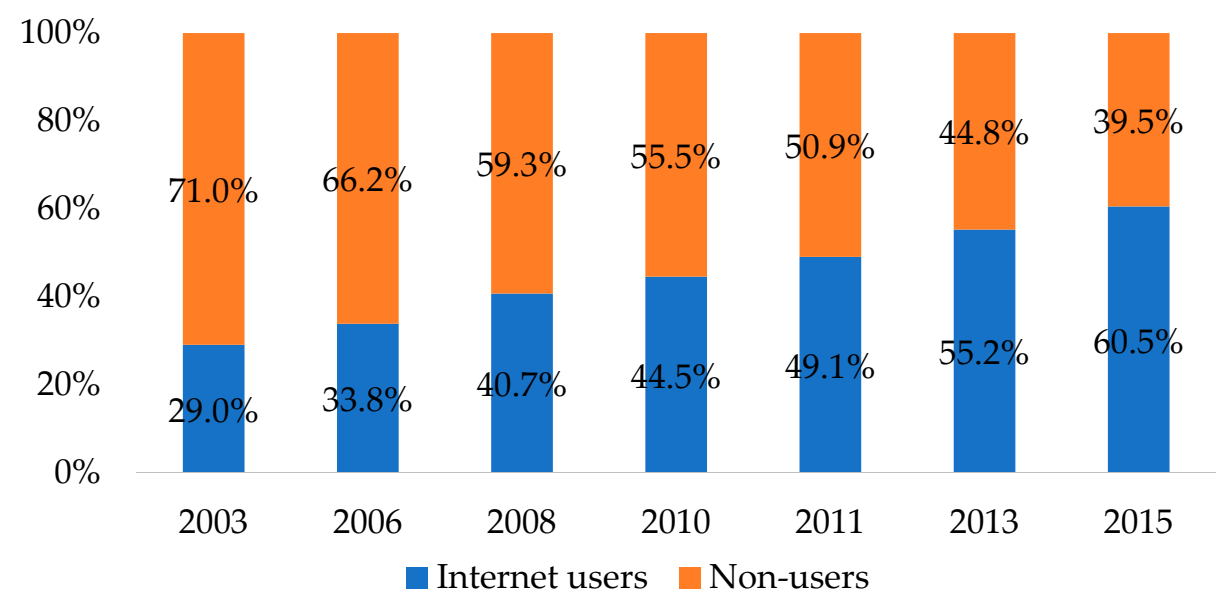

Figure 1. Internet users in relation to non-users. Source: SR2003, SR2006, SR2008, SR2010, SR2011, SR2013, ERC2015. SR2003, $n=2450 ;$ SR2006, $n=2000 ;$ SR2008, $n=1039 ;$ SR2010, $n=1255$; SR2011, $n=1250 ;$ SR2013, $n=1542 ;$ ERC2015, $n=1018$.

\subsection{Internet Use by Key Sociographic Variables}

A bivariate analysis helps to understand that being, or not being, an Internet user is not randomly distributed across contemporary Portuguese society. It is in fact structured by age cohorts, but not only.

\subsubsection{Internet Use by Age Cohorts}

Making an analytical cut across the different age cohorts, Figure 2 clearly shows the effect of this variable. Starting with the most striking value, we realise that $96.3 \%$ of the respondents born between 1991 and 2000 (15-24 years old) described themselves as Internet users, whereas this percentage decreases at every jump in the generational ladder. While in the age cohort of 1981-1990 (25-34) the value is not so different (93.1\%), the drop is more accentuated at every rise in age-between 1971 and 1980 (35-44) with 81.4\%; 1961-1970 (45-54) 63.4\%; 1960-1951 (55-64) 36.1\%; and, in a more contrasting way with the youngest generations, among the respondents born before 1951, we only find $11.5 \%$ of users. Hence, this evidence about a (pre)disposition in Portuguese youth for new media use converges with results unveiled by previous studies.

In fact, if we observe the measures of central tendency, the average age of the total surveyed sample $^{4}$ was 47.4 years, with a standard deviation of 18.5. Now, using the two box plots (Figure 3 ) and focusing on the average age of the Internet users surveyed, we observe that it was 38 (standard deviation of 14), and, among non-users, 62 (also with a standard deviation of 14). Moreover, the comparative analysis of the quartiles supports the fact that non-users tend to be older in Portugal.

4 It must not be forgotten that the minimum threshold for taking part in the 2015 survey was 15 years of age. 


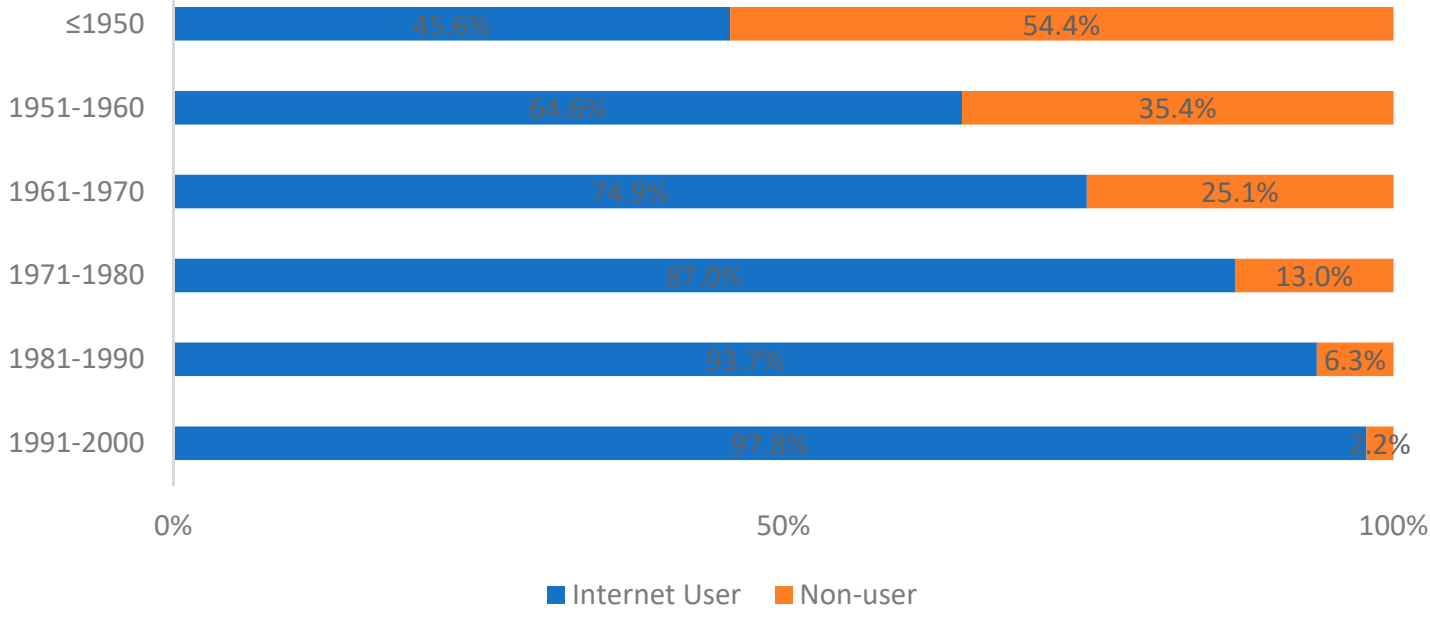

Figure 2. Internet users in relation to non-users, by age cohorts. Source: ERC2015-The new dynamics of audio-visual consumption in Portugal; $n=1018$.

100
90
80
70
60
50
40
30
20
10
0

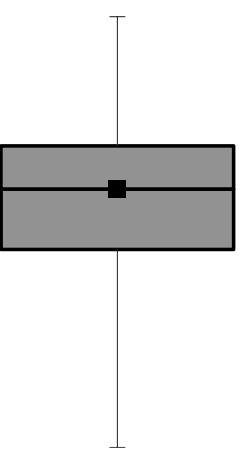

Internet User

Non-user

Figure 3. Box plot of ages: Internet users in relation to non-users. Source: ERC2015-The new dynamics of audio-visual consumption in Portugal; $n=1018$.

However, focusing once again within the youngest, we see that $3.7 \%$ consider themselves non-users. This evidence helps to refute the minimally shared commonsensical view that all young people are equal in what concerns access to ICTs and shows that generational belonging does not suffice to explain the relationship with media since we witness a digital divide even within the younger generation in analysis. This digital divide, even amid Portuguese youth, goes along with findings from former research.

Measuring the strength of the relationship, we have a strong relationship with a Cramer's V of 0.650 and an Eta of 0.650 . Treating age as a continuous variable (not fragmented into different age levels) -which allows us to measure the relationship in a more refined and robust approach -we have an equally strong Pearson's $r^{5}$ of 0.640 . Therefore, corroborating previous findings, there is a statistical

5 Pearson's $r$ is used with two quantitative variables. In this case, as the variable use is dichotomised, this measure might be used, since it is more powerful—just as defended by some authors, namely [91,92]—and allows this type of tests. The simple linear correlation makes it possible to obtain a measure (correlation coefficient-Pearson's $r$ ) through which the strength or intensity of a linear association between two or more variables is determined. 
relationship between the two variables, where the probability of finding an Internet user increases when we look at a younger generation.

\subsubsection{The Importance of Formal Education}

Examining formal education (Figure 4), in relation to the highest level of education completed, we notice there is not a single Internet user among the illiterate in Portugal. Moving on to those who never attended school, but know how to read, we find 3.3\% of users; in the so-called first cycle of education in Portugal (4th year of school), we have $12.7 \%$ of users; and in the second cycle (6th year of school) that percentage increases substantially to $38.4 \%$. However, it is in the third cycle (9th year of school) that we notice a double increase in relation to the previous one (82.9\%). Already at secondary education level, the rate reaches $93 \%$ and, at the level of baccalaureate/intermediary/technological specialisation courses (CET), we have $91.7 \%$. Moving into higher education and, unlike what could be expected, from those who completed a bachelor's degree, $97.6 \%$ claimed to be users—which refers us to $2.4 \%$ of non-users. Finally, at second-level (master's) and third-level (Ph.D.) degrees, all respondents presented themselves as users.

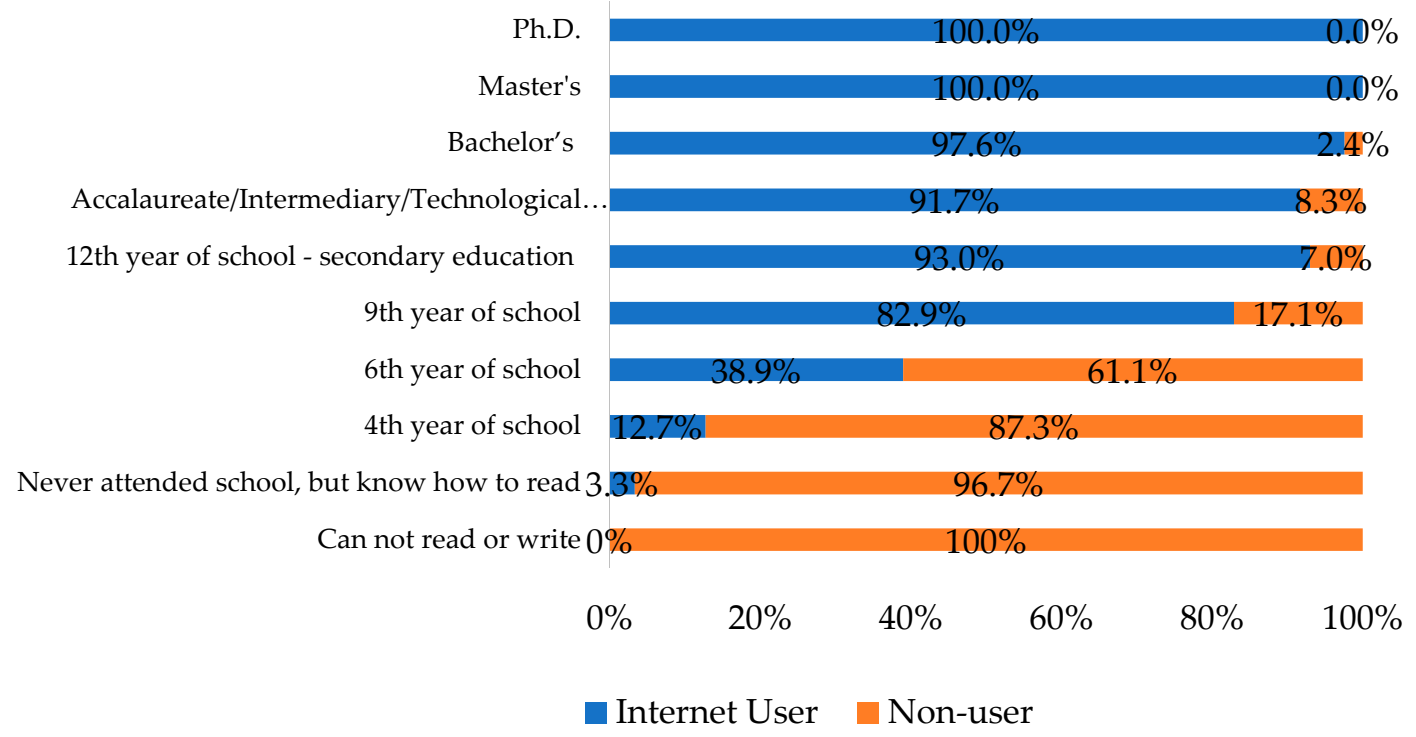

Figure 4. Box plot of ages: Internet users in relation to non-users. Source: ERC2015-The new dynamics of audio-visual consumption in Portugal; $n=1014$ ( 4 respondents chose not to answer- $0.4 \%$ of the total).

Using a Cramer's V to measure the strength of the relationship between the two variables, compared with the remaining variables tested, we get to the strongest value of 0.760 . In sum, in Table 1, ordered in descending order, and by adding other sociologically relevant variables, we understand the explanatory power of education-a variable, without a doubt, closely linked to generation. This evidence is in harmony with previous studies and reinforces the importance of cultural capital in the institutionalized state [93] as a predictor of new media use.

Making use of the several previous rounds of surveys on the network society and measuring the relationship of Internet use with the highest level of education completed ${ }^{6}$ and age in continuous numerical terms ${ }^{7}$, we notice, in a powerful and recurring way, the importance of education in explaining Internet use (Table 2). In a longitudinal view of all the rounds, education was always the variable with greater explanatory force-not the year of birth, although its importance is also great.

\footnotetext{
Cramer's V

Pearson's r.
} 
Table 1. Coefficients of association/correlation with Internet use.

\begin{tabular}{cc}
\hline Independent Variable & Dependent Variable: User or Non-User \\
\hline Level of education completed & Association/Correlation Coefficient \\
Age group & 0.759 \\
Age & 0.650 \\
Work situation & 0.631 \\
Professional group & 0.595 \\
Marital status & 0.482 \\
Net monthly income of the household & 0.417 \\
Net monthly income & $0.401^{*}$ \\
Size of the household, including the respondent & $0.392^{* *}$ \\
Type of employment contract & 0.284 \\
Gender & 0.214 \\
Region of residence (NUTS II) & 0.056 \\
Source: ERC2015-The new dynamics of audio-visual consumption in Portugal; $n=1018 ;{ }^{*} \mathrm{DK} / \mathrm{NA}=435(43 \%) ; *$ \\
DK/NA = 413 (41\%).
\end{tabular}

Table 2. Coefficients of association/correlation with Internet use in previous years.

\begin{tabular}{cccccccc}
\hline & \multicolumn{6}{c}{ Coefficient of the Measure of Association/Correlation } \\
\hline Year of Data Collection & $\mathbf{2 0 0 3}$ & $\mathbf{2 0 0 6}$ & $\mathbf{2 0 0 8}$ & $\mathbf{2 0 1 0}$ & $\mathbf{2 0 1 1}$ & $\mathbf{2 0 1 3}$ & $\mathbf{2 0 1 5}$ \\
\hline $\begin{array}{c}\text { Highest level of education completed } \\
\text { Age }\end{array}$ & 0.597 & 0.591 & 0.658 & 0.662 & 0.685 & 0.707 & 0.759 \\
& 0.469 & 0.537 & 0.516 & 0.585 & 0.520 & 0.613 & 0.631 \\
\hline
\end{tabular}

Source: SR2003, SR2006, SR2008, SR 2010, SR2011, SR2013, ERC2015; SR2003, $n=2450 ;$ SR2006, $n=2000$; SR2008, $n=1039$; SR2010, $n=1255$; SR2011, $n=1250 ;$ SR2013, $n=1542$; ERC2015, $n=1018$.

\subsection{Internet Uses: Online Activities}

Transposing this to Internet uses, we can indicate many different uses of ICTs-from more communicational ones (and, as such, relational and social) to others that are more informational, as well as activities driven by entertainment, consumerism, or online expressive and productive practices.

Focusing on the total surveyed Internet users (Figure 5), in decreasing order of the listed activities, those carried out the most are of the communicational/relational type: $87 \%$ send and receive emails, $79.9 \%$ use websites of online social networks, and $68 \%$ use instant messaging programs ${ }^{8}$. Next in the list, $62.8 \%$ of all Portuguese Internet users usually use the Internet to search for information with recreational purposes; over half (58.9\%) to watch videos by amateurs in sharing websites ${ }^{9}$ and $57.5 \%$ to watch videos by professionals ${ }^{10}$. More informational and news-oriented uses follow, with a little over half (53.6\%) using the Internet to read contents from newspapers or magazines and 52.9\% to search information for professional purposes. Half also use the Internet to make/receive phone calls. With values below the average of Internet users, less than a third (30.4\%) use the Internet to read blogs, $28.4 \%$ to play online games, and $25 \%$ for professional social networks. Moving on to media consumption through the Internet, $22.7 \%$ use it to listen to radio programs and $21.4 \%$ to watch television programs. Finally, only $11.5 \%$ say they take part in online courses and, giving reason to criticisms of an excessive optimism in relation to an apparent growth of a participatory culture in new media [94-97], we witness instead also in Portugal to a participatory divide [98] or digital production gap [99]: only $6.3 \%$ of Portuguese users produce contents for their own blog.

\footnotetext{
8 For example: Messenger, iChat, WhatsApp.

9 The case of YouTube.

10 In official websites of television channels, Internet platforms, YouTube, among others.
} 
Compared to the younger generation of Internet users (Figure 5), the ordering is practically maintained but nearly always with higher values, except in the search for information with professional purposes and in pure news contents, namely the reading of online newspapers and magazines. At the top, we still have a communicational dimension of usage, where $89.2 \%$ of young people use the Internet to send and receive emails, $87.7 \%$ for online social networks, and $86.9 \%$ for instant messaging programs. An audio-visual dimension follows, with $72.3 \%$ using the Internet to watch videos by professionals and $71.5 \%$ to watch videos by amateurs. Moving on to voice communication, but through the Internet, we see $64.6 \%$ of young users making use of online phone calls. We still observe that $62.3 \%$ use the Internet to search for information with recreational purposes. It should be noted that a little over half $(51.5 \%)$ claim to play games online.

Already with values below the average, $46.9 \%$ use the Internet to search for information with professional purposes, $45.4 \%$ to read newspapers or magazines, and $35.4 \%$ to read blogs. The young users who use the Internet to access other traditional media amount to nearly a third, 32.3\% to watch television programs, and $32.3 \%$ to listen to radio programs. Finally, $27.7 \%$ of young Internet users use the Internet for professional social networks, $15.4 \%$ to take part in online courses, and only $6.2 \%$ to work on their own blog.

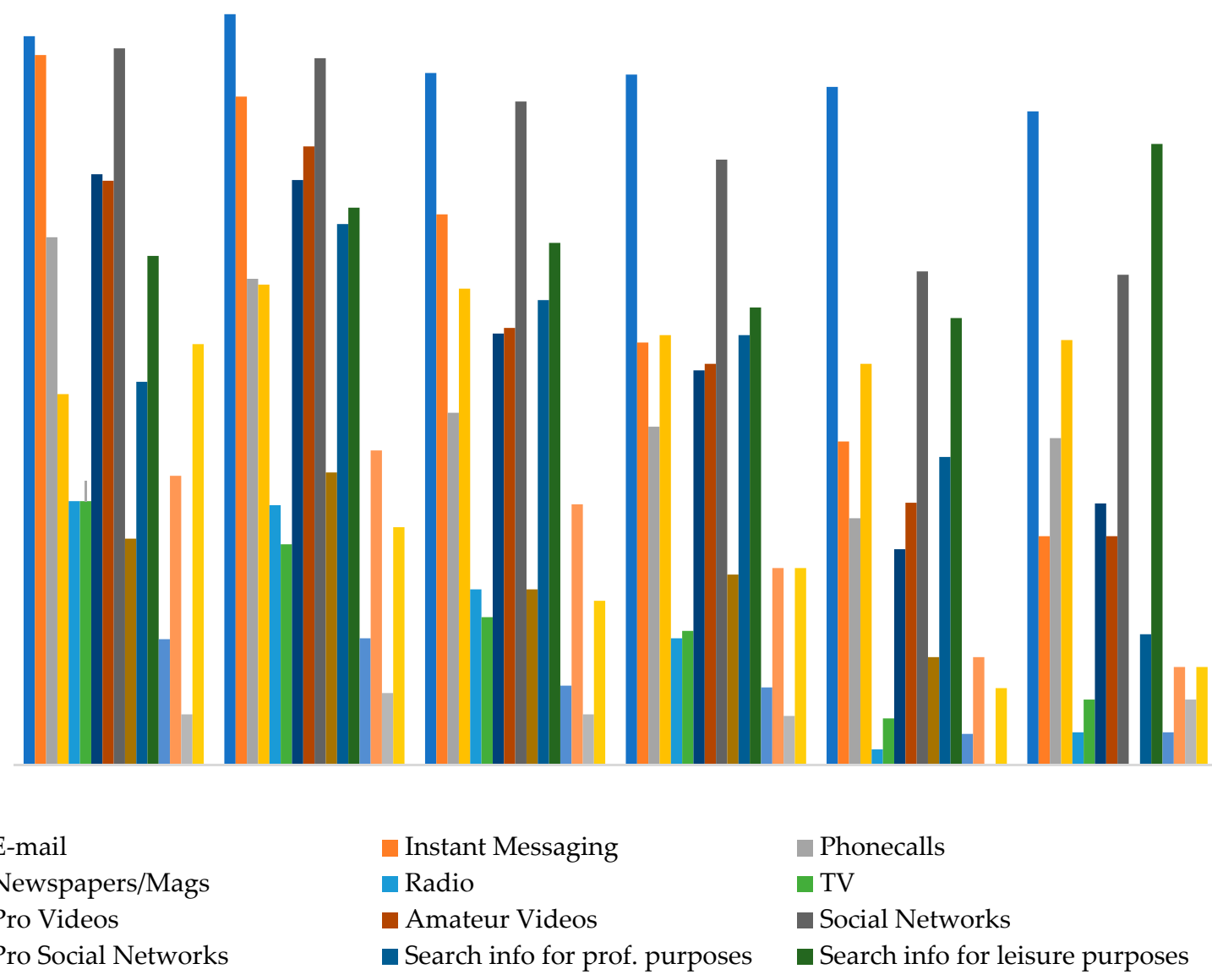

Figure 5. Activities carried out online by generation. Source: ERC2015-The new dynamics of audio-visual consumption in Portugal; $n=616$. 
Creating an index ${ }^{11}$ with these 16 activities ${ }^{12}$ and then measuring it with age ${ }^{13}$, we obtained a correlation coefficient of -0.617 . Therefore, we have a negative correlation of strong magnitude: the more age goes up, the more the cumulative number of activities carried out online decreases.

In the 2013 version, a quantitative index including a battery of 71 online activities (spanning the dimensions of communication, entertainment, information, user-generated contents, goods and services, and social networks) was combined. Relating this index with the variable age in scale, an average negative correlation (-0.589) was also found. Likewise, in 2010, creating indexes for activities of communication ${ }^{14}$, information ${ }^{15}$, entertainment ${ }^{16}$, user-generated contents ${ }^{17}$, goods and service ${ }^{18}$, education ${ }^{19}$, and measuring the association with age groups, significant values were found in the measures of correlation ${ }^{20}$ - except for the correlation with the indexes goods and services and age. The correlation was negative, in the sense that the levels of use were higher in the younger ages and would decrease in more advanced ages. In other words, the more varied uses would decrease as age would go up. Hence, in a recurring way in all the survey rounds analysed, the more one advances in the age cohort of the sample, the smaller was the number of accumulated online activities and, therefore, the number of users not involved with this type of resources was superior.

\subsection{Media Preferences}

Broader media consumption, beyond new media alone, seems to be increasingly wider, diversified, fragmented, and structured through several media, whether this phenomenon is called "cross-media" [100,101], "polymedia" [102], "transmedia" [103,104] or "media manifold" [105]. Now, this progressive mediation and cross use of several media further complicates a holistic view of media choices that is vigilant towards the consumption of each individual across different media and devices, whether theoretical one calls it media diets ${ }^{21}$ [106] or media repertoires [107-110].

Measuring the growing plurality of uses in a combined way and across the different media seems to be increasingly difficult $[111]^{22}$. In view of space limitations, we chose to use a variable with, we believe, a high heuristic potential. It implies ranking the importance of the different media and activities (television, radio, print newspapers/magazines, Internet, video games) and selecting the favoured medium in everyday life.

Television and its consumption are clearly central: when confronted with this choice, from the total population, more than half $(65.5 \%)$ chose it as their favourite medium from which they could not be deprived on daily life. Second, we have the Internet among $26.7 \%$ of the respondents, then the radio (chosen by $4.4 \%$ ), and $2.6 \%$ prefer to read newspapers and/or magazines. Finally, with minor relevance, we have video games for $0.8 \%$ of the respondents.

With these national figures set out, is there anything specific about the relationship of the youngest age cohorts with media? A bivariate analysis shows that the orderings vary according to the age groups, almost promoting a ladder effect (Figure 6). Contrastingly, whereas the Internet is the most

11 With a Cronbach's alpha coefficient of 0.922 , which provides safety on the reliability of the measurement scale, i.e., they are measuring the same.

12 All the online activities were added up. Consequently, the scale ranged from 0 (none, either because the respondent was not a user or because $\mathrm{s} /$ he did not carry it out) to 16 activities.

13 Treating it as numerical and, therefore, using a Pearson's r.

14 Chronbach's alpha of 0.7437 .

15 Chronbach's alpha of 0.8027 .

16 Chronbach's alpha of 0.8882 .

17 Chronbach's alpha of 0.9246 .

18 Chronbach's alpha of 0.8219 .

19 Chronbach's alpha of 0.7150 .

Pearson's r.

21 A concept that refers to the combined whole of daily media choices, continued over time, at the level of practices, consumption, and lifestyles.

22 Notice that this need for an overall framework for the different media had already been subscribed by Katz et al. [112] when analysing mass media in the seventies-so it is not a true novelty. 
important activity for the young generation, receiving $66.7 \%$ of the votes (against $28.1 \%$ for television), in the sample of respondents aged above 64 the importance of television is overwhelming- $90.3 \%$ (against $2.8 \%$ for the Internet), with radio in the lead (4.6\%) in this age group.

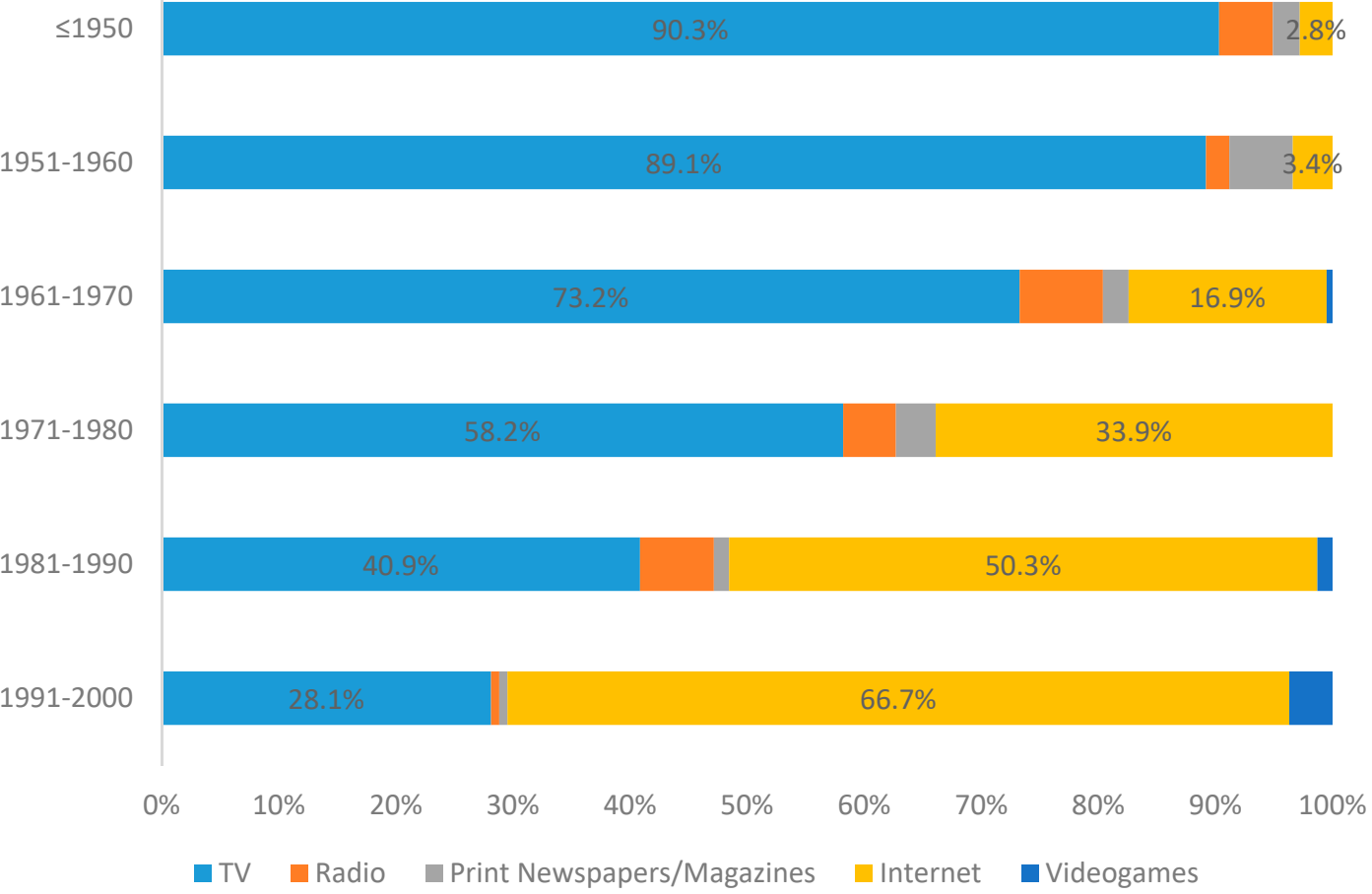

Figure 6. Most difficult activity to give up, by age cohort. Source: ERC2015-The new dynamics of audio-visual consumption in Portugal; $n=1018$.

Moving this to a multivariate analysis of the same question and bringing in some of the sociographic variables ${ }^{23}$ we have previously seen on this article to embrace greater sociological relevance and explanatory power vis-à-vis the different relationships with media, an interesting social phenomenon is observed.

To carry this exercise out, a multiple correspondence analysis was conducted with the aim of graphically representing the data on social context together with this key variable (media preferences), since this technique enables an integrated view of the structural interdependencies among the multiple variables in question, managing the multidimensionality of their relationships. Graphically projecting these variables as quantifications facilitates a topological reading and its corresponding comprehension, allows us to interpret and clarify the relational structure underlying the relationship dynamics between the participating variables. As a methodological reminder, it should be mentioned that these are favoured associations, which does not mean that the whole subsample displays all of the distinct and distinctive features of each profile.

Starting our analysis in the first quadrant $(+\mathrm{X} ;+\mathrm{Y})$ on Figure 7 , by quantifying the categories, we see a favoured association between those married, with average to low educational qualifications (second and first cycle of education, respectively), aged between 45 and 64, and those who prefer more traditional media like television or print newspapers and magazines. 
Right opposite to these profiles, in the second quadrant $(-X ;+Y)$ we have- and by comparison with the first dimension, structured according to age and educational capital—respondents with an average or very high educational capital (third cycle of education and $\mathrm{PhD}$, respectively), between the ages of 35 and 44 , divorced or separated, closer to the radio. The third quadrant $(-X ;-Y)$ points to a favoured trend associating the categories of young people (15-24) and young adults, who are single or in non-marital partnership and have completed secondary education, a bachelor or master's degree, being closer to the Internet and videogames.

Finally, focusing on the fourth quadrant $(+X ;-Y)$, we have an older population profile (65 or more years of age), with little or no education, widowed, and more connected to the television. Within this type, which points to the most common and overrepresented categories in each subgroup-where space is essentially structured by age and education (dimension 1) and marital status (dimension 2), these social profiles are the most distanced from a digital and networked way of life. In other words, they are in the field of digital exclusion and, therefore and concurrently, social exclusion.

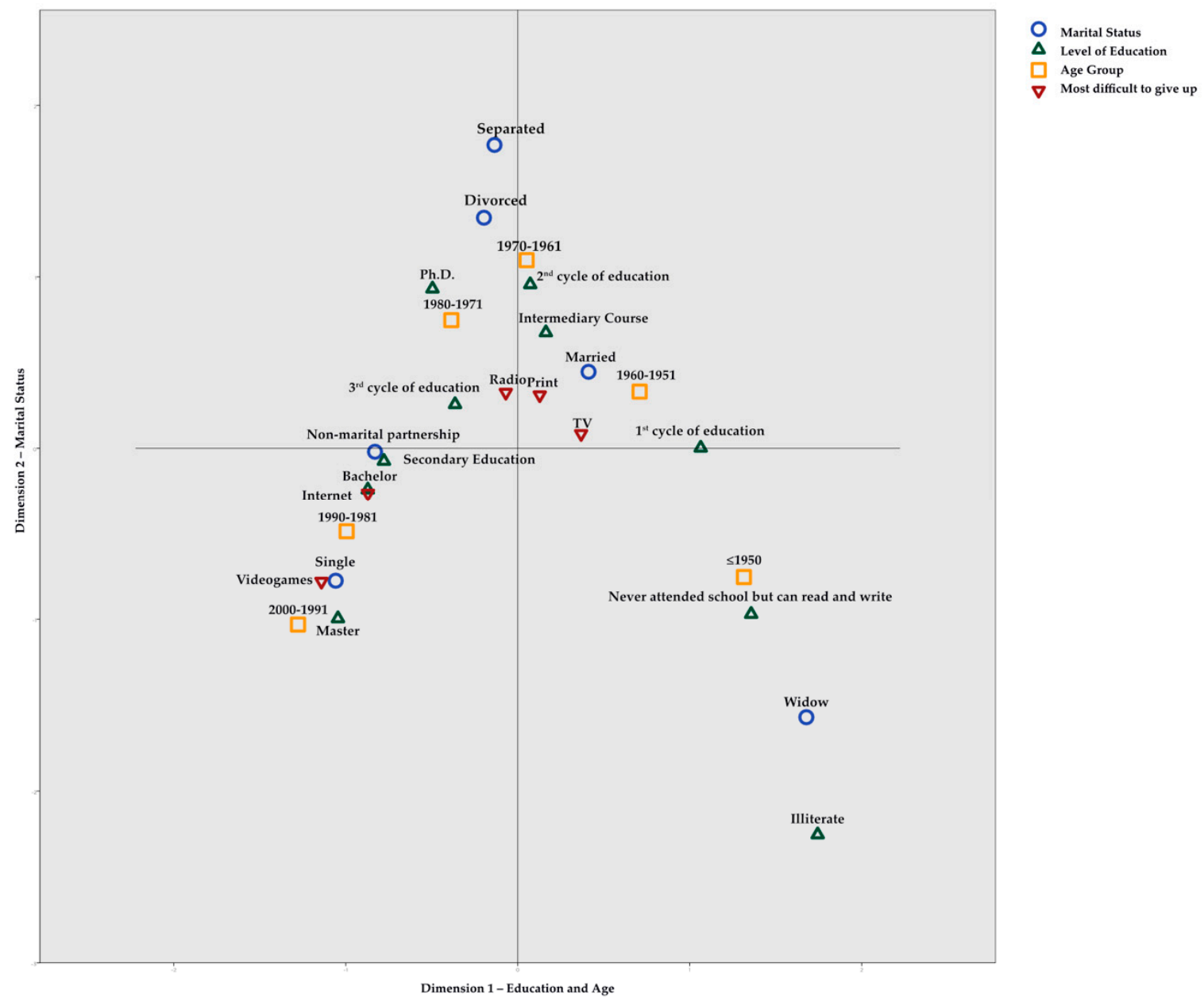

Figure 7. Multiple correspondence analysis. Source: ERC2015-The new dynamics of audio-visual consumption in Portugal; $n=1018$.

\section{Discussion}

This article attempted to contribute to a reflection on the relationships of Portuguese generations with media by providing some empirical clues based on a quantitative methodology and an age cohort analysis focusing on youth.

The centrality of mediation was demonstrated, whether this mediation is digital and networked, or done through the more traditional media. Television seems to still act as a strong vector structuring 
national media repertoires, particularly among the older generations who elect it as their favourite medium. However, with greater incidence in the younger generations, the emergence of digital and networked media repertoires and cumulative consumption patterns is noticed and here the importance of television seems to dilute itself, bearing in mind the atomisation, but also the convergence, of mediation platforms.

Concerning the Internet, the younger age cohorts are those who ascribe greater importance to it, preferring entertainment uses to traditional news information (when compared to other generations). However, intra- and inter-generational diversity reigns in Portugal. Inequalities in access and uses were demonstrated by a cross-generational analysis, which helps to deconstruct certain types of discursive rhetoric of the so-called digital generation based solely on age or of digital natives as a homogeneous global whole.

In fact, through bivariate and multivariate readings, the co-importance of formal education in shaping media uses was recaptured. The interpretation of the graphs allowed to perceive favoured associations between some attributes of social contextualisation and their relationships with media. The younger generations, with more institutionalized cultural capitals and not in a formal partnership, tend to ascribe more importance to new media. It is certainly important not to forget that the different relationships with media are not only shaped according to the generation, but also by individual life courses, contexts and resources, as well as by what people do with technology and why-what is their involvement and engagement, what are their particular motivations.

\section{Conclusions}

Returning to the main research question (RQ) of this paper-is there, in the Portuguese context, anything particular about the relationship of youth with media?-some conclusions can be drawn. The statistical analysis showed that there are specificities of the relationship of Portuguese youth with media that set them apart from the older age cohorts.

So, are there different patterns of Internet use in Portugal (SRQ 1.1)? Is Portuguese youth more predisposed to new media use and online activities than the older generations (SRQ 1.2)? Indeed, different patterns of Internet use in Portugal where discovered in this longitudinal analysis. In all of the scrutinised years, Portuguese youth tended to dedicate more time to online activities than the older generations. Nonetheless, can we relate these differences to age cohorts (SRQ 1.3)? Age is important, but these intergenerational differences cannot be explained solely on the basis of the age criterion, since variations in inter-age cohorts were found in the samples.

Regarding the subsidiary research questions relating to media preferences in Portugal, do different age cohorts prefer different media-youth favouring new media vs. elderly generations favouring mass media (SRQ 2.1)? Younger age cohorts said they preferred new media in daily life, in contrast with the elderly generations, which preferred television. Hence, not all the Portuguese are the same with regard to (new) media uses and representations, and age seems to be an important variable to consider. However, can these differences be explained solely on the basis of age cohorts (SRQ 2.2)? No, since homogenous age blocks were not found.

Generational commonalities, such as a shared history, social, and cultural frames, but also a particular and situated media environment, seem to be important but are not sufficient to produce sharp different modes of media use and appraisal. These differences cannot be explained solely by generational belonging or age cohorts. This kind of reasoning can shade internal differences and crystallise a false sense of unity among individuals born in the same space-time macro context, since not all coevals will experience the same event in the same way-there are always differences in social context at a more micro level, as well as biographical specificities.

This paper attempted to link social demography with patterns of preference and use of (new) media, while also overcoming the reductionism of cohort analysis by introducing other social variables into the discussion. This exercise shed light on inter- and intra-age cohort specificities, but also on heterogeneity, which can be explained by education and other important variables. 
As a limitation of the study, focusing merely on quantitative data collection can obscure finer relationships and nuances that escape the large sieve of extensive research methods. More qualitative and mixed methods are needed in order to better and holistically understand relations with media. Additionally, as already stated [86,88], future research agendas should explore the life course as a critical dimension in shaping people's relationships with media. Future research should move beyond a demographic approach to media uses and summon not only social and cultural forces and processes, but also biographical traits that, together and dialectically, shape different forms of social appropriation of media. With that research programme in mind, in order to analyse the individual and societal level, agency and structure, contextualised in space and time, life story interviews could be useful to, in a sociological sense, be able to "hear, behind the solo of a human voice, the music of society and culture in the background" [113] (p. 168).

All in all, we should not deny a kind of generational order, but it is important to acknowledge that it must be intersected by other variables. The generation concept is essential to understand the different types of relationships the Portuguese establish with media "insofar as it keeps its complexity" [34] (p. 187), because it does not explain everything-instead, it conceals a large variety of media uses, domestications, preferences, and repertoires.

Funding: The translation of this research was funded by the Portuguese National Funding Agency for Science, Research and Technology (FCT) Strategic Financing: UID/SOC/03126/2013.

Conflicts of Interest: The authors declare no conflict of interest.

\section{References}

1. White, J. Thinking generations. Br. J. Sociol. 2013, 64, 216-247. [CrossRef] [PubMed]

2. Woodman, D. The sociology of generations and youth studies. In Routledge Handbook of Youth and Young Adulthood; Furlong, A., Ed.; Routledge: London, UK, 2016; pp. 20-26, ISBN 978-1138804357.

3. Livingstone, S. On the Mediation of Everything: ICA Presidential Address 2008. J. Commun. 2009, 59, 1-18. [CrossRef]

4. Couldry, N.; Hepp, A. The Mediated Construction of Reality; Polity Press: Cambridge, UK, 2017.

5. Deuze, M. Media Life; Polity Press: Cambridge, UK, 2012; ISBN 978-0-7456-4999-3.

6. Silverstone, R. Why Study the Media; Sage: London, UK, 1999; ISBN 0-7619-6454-1.

7. Thompson, J.B. The Media and Modernity: A Social Theory of the Media; Polity Press: Cambridge, UK, 1995.

8. Ryder, N.B. The Cohort as a Concept in the Study of Social Change. Am. Sociol. Rev. 1965, 30, $843-861$. [CrossRef] [PubMed]

9. Manheim, K. The Problem of Generations. In Essays on the Sociology of Knowledge; Kecskemeti, P., Ed.; Routledge \& Kegan Paul: London, UK, 1952; pp. 276-322, ISBN 9780710033079.

10. Spitzer, A.B. The Historical Problem of Generations. Am. Hist. Rev. 1973, 78, 1353-1385. [CrossRef]

11. Kertzer, D.I. Generation as a sociological problem. Annu. Rev. Sociol. 1983, 9, 125-149. [CrossRef]

12. Pilcher, J. Mannheim's sociology of generations: An undervalued legacy. Br. J. Sociol. 1994, 45, 481-495. [CrossRef]

13. Eyerman, R.; Turner, B.S. Outline of a Theory of Generations. Eur. J. Soc. Theory 1998, 1, 91-106. [CrossRef]

14. Corsten, M. The Time of Generations. Time Soc. 1999, 8, 249-272. [CrossRef]

15. Aboim, S.; Vasconcelos, P. From political to social generations. Eur. J. Soc. Theory 2013, 17, 165-183. [CrossRef]

16. Edmunds, J.E.; Turner, B.S. Generations, Culture and Society; Open University Press: Buckingham, UK, 2002; ISBN 978-0335208517.

17. Purhonen, S. Generations on paper: Bourdieu and the critique of "generationalism". Soc. Sci. Inf. 2015, 55, 94-114. [CrossRef]

18. Gumpert, G.; Cathcart, R. Media grammars, generations, and media gaps. Crit. Stud. Mass Commun. 1985, 2, 23-35. [CrossRef]

19. Prensky, M. Digital Natives, Digital Immigrants Part 1. Horizon 2001, 9, 1-5. [CrossRef]

20. Prensky, M. Digital Natives, Digital Immigrants Part 2: Do They Really Think Differently? Horizon 2001, 9 , 1-6. [CrossRef] 
21. Tapscott, D. Growing Up Digital: The Rise of the Net Generation; McGraw-Hill: New York, NY, USA, 1998; ISBN 978-0071347983.

22. Rheingold, H. Smart Mobs: The Next Social Revolution; Basic Books: New York, NY, USA, 2002; ISBN 978-0738208619.

23. Feixa, C. Generación @ la juventud en la era digital. Nómadas (Col) 2000, 13, 75-91.

24. Feixa, C. De la Generación@ a la \#Generación: La Juventud en la era Digital; NED: Barcelona, Spain, 2014; ISBN 978-84-942364-6-4.

25. Huang, H. Social Media Generation in Urban China; Springer: Berlin, Germany, 2014; ISBN 978-3-642-45440-0.

26. Taipale, S. Synchronicity matters: Defining the characteristics of digital generations. Inf. Commun. Soc. 2016, 19, 80-94. [CrossRef]

27. Sackmann, R.; Winkler, O. Technology generations revisited: The internet generation. Gerontechnology 2013, 11, 493-503. [CrossRef]

28. Bennett, S.; Maton, K.; Kervin, L. The "digital natives" debate: A critical review of the evidence. Br. J. Educ. Technol. 2008, 39, 775-786. [CrossRef]

29. Herring, S. Questioning the generational divide: Technological exoticism and adult constructions of online youth identity. In Youth, Identity, and Digital Media; Buckingham, D., Ed.; MIT Press: Cambridge, MA, USA, 2008; pp. 71-92.

30. Helsper, E.J.; Eynon, R. Digital natives: Where is the evidence? Br. Educ. Res. J. 2010, 36, 503-520. [CrossRef]

31. Bennett, S.J.; Maton, K.A. Beyond the 'digital natives' debate: Towards a more nuanced understanding of students' technology experiences. J. Comput. Assist. Learn. 2010, 5, 321-331. [CrossRef]

32. Kennedy, G.; Judd, T.; Dalgarno, B.; Waycott, J. Beyond natives and immigrants: Exploring types of net generation students. J. Comput. Assist. Learn. 2010, 26, 332-343. [CrossRef]

33. Thomas, M. Deconstructing Digital Natives: Young People, Technology and the New Literacies; Thomas, M., Ed.; Routledge: New York, NY, USA, 2011; ISBN 0-203-81884-9.

34. Aroldi, P.; Colombo, F. Questioning "digital global generations." A critical approach. North. Lights 2013, 11, 175-190. [CrossRef]

35. Buckingham, D. Is there a digital generation? In Digital Generations: Children, Young People, and the New Media; Buckingham, D., Willett, R., Eds.; Lawrence Erlbaum Associates: Mahwah, NJ, USA, 2006; pp. 1-13, ISBN 0-805-85862-8.

36. Buckingham, D. Making Sense of the "Digital Generation": Growing Up with Digital Media. Self Soc. 2013, 40,7-15. [CrossRef]

37. Ito, M.; Baumer, S.; Bittanti, M.; Boyd, D.M.; Cody, R.; Herr-Stephenson, B.; Horst, H.A. Hanging Out, Messing Around, and Geeking Out: Kids Living and Learning with New Media; MIT Press: Cambridge, MA, USA, 2010; ISBN 978-0-262-01336-9.

38. Buckingham, D.; Kehily, M.J. Introduction: Rethinking Youth Cultures in the Age of Global Media. In Rethinking Youth Cultures in the Age of Global Media; Buckingham, D., Bragg, S., Kehily, M.J., Eds.; Palgrave Macmillan: Hampshire, UK, 2014; pp. 1-31, ISBN 978-1-137-00814-5.

39. Bourdieu, P. 'Youth' is just a word. In Sociology in Question; Sage: Thousand Oaks, CA, USA, 1993; pp. 94-102, ISBN 0-8039-8338-7.

40. Buckingham, D.; Willett, R. Digital Generations: Children, Young People, and the New Media; Lawrence Erlbaum Associates: Mahwah, NJ, USA, 2006; ISBN 0-805-85862-8.

41. Giele, J.Z.; Glen, H. (Eds.) Methods of the Life Course Research. Qualitative and Quantitative Approaches; Sage: London, UK, 1998; ISBN 978-0761914372.

42. Buckingham, D. Foreword. In Deconstructing Digital Natives; Thomas, M., Ed.; Routledge: New York, NY, USA, 2011; ISBN 0-203-81884-9.

43. Haddon, L. Social Media and Youth. In The International Encyclopedia of Digital Communication and Society; Mansell, R., Ang, P.H., Eds.; John Wiley \& Sons, Inc.: Hoboken, NJ, USA, 2015; Volume 11, pp. 1-9, ISBN 9781118290743.

44. Mackay, H.; Gillespie, G. Extending the Social Shaping of Technology Approach: Ideology and Appropriation. Soc. Stud. Sci. 1992, 22, 685-716. [CrossRef]

45. Wajcman, J. Addressing Technological Change: The Challenge to Social Theory. Curr. Sociol. 2002, 50, 347-363. [CrossRef] 
46. Selwyn, N. Making sense of young people, education and digital technology: The role of sociological theory. Oxf. Rev. Educ. 2012, 38, 81-96. [CrossRef]

47. Mills, C.W. The Sociological Imagination; Oxford University Press: New York, NY, USA, 2010; ISBN 978-0-19-513373-8.

48. MacKenzie, D.A.; Wajcman, J. (Eds.) The Social Shaping of Technology: How the Refrigerator Got its Hum, 2nd ed.; Open University Press: Philadelphia, PA, USA, 1999; ISBN 9780335199136.

49. Williams, R.; Edge, D. The social shaping of technology. Res. Policy 1996, 25, 865-899. [CrossRef]

50. Bijker, W.E.; Hughes, T.P.; Pinch, T. The Social Construction of Technological Systems: New Directions in the Sociology and History of Technology (Anniversary Edition); Bijker, W.E., Hughes, T.P., Pinch, T., Eds.; MIT Press: Cambridge, MA, USA, 2012; ISBN 978-0-262-51760-7.

51. Bijker, W.E.; Law, J. Shaping Technology/Building Society: Studies in Sociotechnical Change; Bijker, W.E., Law, J., Eds.; MIT Press: Cambridge, MA, USA, 1992; ISBN 0-262-02338-5.

52. Silverstone, R.; Hirsch, E. (Eds.) Consuming Technologies: Media and Information in Domestic Spaces; Routledge: London, UK, 1994; ISBN 0415117127.

53. Silverstone, R.; Haddon, L. Design and the domestication of information and communication technologies: Technical change and everyday life. In Communication by Design: The Politics of Information and Communication Technologies; Mansell, R., Silverstone, R., Eds.; Oxford University Press: Oxford, UK, 1996; pp. 44-74, ISBN 9780198289418.

54. Haddon, L. Information and Communication Technologies in Everyday Life: A Concise Introduction and Research Guide; Berg: Oxford, UK, 2004; ISBN 1-85973-798-6.

55. Berker, T.; Hartmann, M.; Punie, Y.; Ward, K.J. (Eds.) Domestication of Media and Technology; Open University Press: Berkshire, UK, 2006; ISBN 9780335217687.

56. Haddon, L. Domestication and the Media. In The International Encyclopedia of Media Effects; Rössler, P., Ed.; John Wiley \& Sons, Inc.: Hoboken, NJ, USA, 2017; Volume 2, pp. 1-10.

57. Oudshoorn, N.; Pinch, T.J. How Users Matter. The Co-construction of Users and Technology; Oudshoorn, N., Pinch, T., Eds.; MIT Press: Cambridge, MA, USA, 2003; ISBN 0-262-15107-3.

58. Van Dijk, J.A.G.M. The Deepening Divide: Inequality in the Information Society; Sage: London, UK, 2005; ISBN 978-1412904032.

59. Boyd, D.M. It's Complicated: The Social Lives of Networked Teens; Yale University Press: New Haven, CT, USA, 2014; ISBN 978-0-300-16631-6.

60. Eastin, M.S.; Cicchirillo, V.; Mabry, A. Extending the Digital Divide Conversation: Examining the Knowledge Gap Through Media Expectancies. J. Broadcast. Electron. Media 2015, 59, 416-437. [CrossRef]

61. Hargittai, E. Second-level Digital Divide: Differences in People's Online Skills. First Monday $2002,7$. [CrossRef]

62. Van Deursen, A.J.A.M.; van Dijk, J.A.G.M. Toward a Multifaceted Model of Internet Access for Understanding Digital Divides: An Empirical Investigation. Inf. Soc. 2015, 31, 379-391. [CrossRef]

63. Van Deursen, A.J.A.M.; van Dijk, J.A.G.M. The digital divide shifts to differences in usage. New Media Soc. 2014, 16, 507-526. [CrossRef]

64. Brandtzæg, P.B.; Heim, J.; Karahasanović, A. Understanding the new digital divide-A typology of Internet users in Europe. Int. J. Hum.-Comput. Stud. 2011, 69, 123-138. [CrossRef]

65. Lenhart, A.; Horrigan, J.B. Re-Visualizing the Digital Divide as a Digital Spectrum. IT Soc. 2003, 1, $23-39$.

66. Loos, E. Senior citizens: Digital immigrants in their own country? Observatorio (OBS*) 2012, 6, 1-23.

67. DiMaggio, P.; Hargittai, E.; Celeste, C.; Shafer, S. Digital Inequality: From Unequal Access to Differentiated Use. In Social Inequality; Neckerman, K., Ed.; Russell Sage Foundation: New York, NY, USA, 2004; pp. 355-400, ISBN 978-0871546210.

68. Wei, K.-K.; Teo, H.-H.; Chan, H.C.; Tan, B.C.Y. Conceptualizing and Testing a Social Cognitive Model of the Digital Divide. Inf. Syst. Res. 2011, 22, 170-187. [CrossRef]

69. Van Deursen, A.J.A.M.; Helsper, E.J. The Third-Level Digital Divide: Who Benefits Most from Being Online? In Communication and Information Technologies Annual: Digital Distinctions and Inequalities Studies in Media and Communications; Emerald Group Publishing Limited: Bingley, UK, 2015; Volume 10, pp. $29-52$.

70. Scheerder, A.; van Deursen, A.J.A.M.; van Dijk, J.A.G.M. Determinants of Internet skills, uses and outcomes. A systematic review of the second- and third-level digital divide. Telemat. Inf. 2017, 34, 1607-1624. [CrossRef] 
71. Van Deursen, A.J.; Helsper, E.J. Collateral benefits of Internet use: Explaining the diverse outcomes of engaging with the Internet. New Media Soc. 2017, 6, 1-19. [CrossRef]

72. Miller, D.; Slater, D. The Internet: An Ethnographic Approach; Berg: Oxford, UK, 2000; ISBN 1859733891.

73. Baym, N.K. Personal Connections in the Digital Age; Polity: Cambridge, UK, 2010; ISBN 978-0-7456-4331-1.

74. Rainie, L.; Wellman, B. Networked. The New Social Operating System; MIT Press: Cambridge, MA, USA, 2012; ISBN 978-0-262-01719-0.

75. Bennett, A.; Robards, B. Mediated Youth Cultures. The Internet, Belonging and New Cultural Configurations; Palgrave Macmillan: Hampshire, UK, 2014; ISBN 978-1-349-44945-3.

76. Hasebrink, U.; Hepp, A. How to research cross-media practices? Investigating media repertoires and media ensembles. Convergence 2017, 23, 362-377. [CrossRef]

77. Aroldi, P.; Colombo, F. Generational belonging and mediascape in Europe. J. Soc. Sci. Educ. 2007, 6, 34-44.

78. Cavalli, A. Generations and Value Orientations. Soc. Compass 2016, 51, 155-168. [CrossRef]

79. Bolin, G. Passion and nostalgia in generational media experiences. Eur. J. Cult. Stud. 2016, 19, $250-264$. [CrossRef]

80. Bolin, G. Media Generations: Objective and subjective media landscapes and nostalgia among generations of media users. Particip. J. Audience Recept. Stud. 2014, 11, 108-131.

81. Hargittai, E. Digital Na(t)ives? Variation in Internet Skills and Uses among Members of the "Net Generation". Sociol. Inq. 2010, 80, 92-113.

82. Zimic, S. Not so 'techno-savvy': Challenging the stereotypical images of the "Net generation". Digit. Cult. Educ. 2009, 1, 129-144.

83. Livingstone, S.; Helsper, E.J. Gradations in digital inclusion: Children, young people and the digital divide. New Media Soc. 2007, 9, 671-696. [CrossRef]

84. Colombo, F.; Fortunati, L. Broadband Society and Generational Changes; Peter Lang: Frankfurt, Germany, 2011; ISBN 978-3-631-60419-9.

85. Loos, E.; Haddon, L.; Mante-Meijer, E. (Eds.) Generational Use of New Media; Ashgate: Farnham, UK, 2012; ISBN 9781409483434.

86. Nixon Paul, G.; Rawal, R.; Funk, A. Digital Media Usage Across the Life Course; Routledge: Oxfordshire, UK, 2016; ISBN 978-1-4724-5580-2.

87. Bolin, G. Media Generations; Routledge: Oxfordshire, UK, 2017; ISBN 9781315694955.

88. Taipale, S.; Wilska, T.; Gilleard, C. (Eds.) Digital Technologies and Generational Identity; Routledge: Oxfordshire, UK, 2018; ISBN 978-1-315-39862-4.

89. Burnett, J. Generations: The Time Machine in Theory and Practice; Ashgate: Surrey, UK, 2010; ISBN 978-1-4094-0980-9.

90. Reisdorf, B.C.; Groselj, D. Internet (non-)use types and motivational access: Implications for digital inequalities research. New Media Soc. 2015, 19. [CrossRef]

91. Blaikie, N.W.H. Analyzing Quantitative Data: From Description to Explanation; Sage: London, UK, 2003; ISBN 0-7619-6758 3.

92. De Vaus, D. Surveys in Social Research, 6th ed.; Routledge: Oxfordshire, UK, 2014; ISBN 978-0-415-53018-7.

93. Bourdieu, P. The forms of Capital. In Handbook of Theory and Research for the Sociology of Education; Richardson, J.R., Ed.; Greenwood Press: Westport, CT, USA, 1986; pp. 241-258.

94. Van Dijk, J. Users like you? Theorizing agency in user-generated content. Media Cult. Soc. 2009, 31, 41-58. [CrossRef]

95. Blank, G. Comment Social Stratification and Content Production. Inf. Commun. Soc. 2013, 16, 999-1004. [CrossRef]

96. Blank, G. Who Creates Content. Inf. Commun. Soc. 2013, 16, 590-612. [CrossRef]

97. Fuchs, C. Social Media: A Critical Introduction, 2nd ed.; Sage: London, UK, 2017; ISBN 978-1-4739-6682-6.

98. Hargittai, E.; Walejko, G. The Participation Divide: Content Creation and Sharing in the Digital Age. Inf. Commun. Soc. 2008, 11, 239-256. [CrossRef]

99. Schradie, J. The digital production gap: The digital divide and Web 2.0 collide. Poetics 2011, 39, $145-168$. [CrossRef]

100. Mascheroni, G.; Pasquali, F.; Scifo, B.; Sfardini, A.; Stefanelli, M.; Vittadini, N. Young Italians' Cross-media Cultures. Obs. $\left(O B S^{*}\right)$ J. 2008, 4, 1-20. 
101. Bjur, J.; Schrøder, K.; Hasebrink, U.; Courtois, C.; Adon, H.; Nossek, H. Cross-media use: Unfolding complexities in contemporary audiencehood. In Transformations: Shifting Audience Positions in Late Modernity; Carpentier, N., Schrøder, K.C., Hallet, L., Eds.; Routledge: London, UK, 2014; pp. 15-29, ISBN 978-020352316-2.

102. Madianou, M.; Miller, D. Polymedia: Towards a new theory of digital media in interpersonal communication. Int. J. Cult. Stud. 2013, 16, 169-187. [CrossRef]

103. Jenkins, H. Transmedia Storytelling. Technolog Review. 2003. Available online: https://www. technologyreview.com/s/401760/transmedia-storytelling/ (accessed on 31 July 2018).

104. Evans, E. Transmedia Television: Audiences, New Media, and Daily Life; Routledge: New York, NY, USA, 2011; ISBN 978-0-415-88292-7.

105. Couldry, N. Media, Society, World: Social Theory and Digital Media Practice; Polity: Cambridge, UK, 2012; ISBN 13 978-0-7456-3920-8.

106. Aroldi, P.; Colombo, F. La età Della TV: Indagine su Quattro Generazioni di Spettatori Italiani; Vita \& Pensiero: Milano, Italy, 2003; ISBN 9788834307564.

107. Van Rees, K.; van Eijck, K. Media repertoires of selective audiences: The impact of status, gender, and age on media use. Poetics 2003, 31, 465-490. [CrossRef]

108. Hasebrink, U.; Popp, J. Media repertoires as a result of selective media use. A conceptual approach to the analysis of patterns of exposure. Communications 2006, 31, 369-387. [CrossRef]

109. Hasebrink, U.; Domeyer, H. Media repertoires as patterns of behaviour and as meaningful practices: A multimethod approach to media use in converging media environments. Particip. J. Audience Recept. Stud. 2012, 9, 757-779.

110. Kim, S.J. A repertoire approach to cross-platform media use behavior. New Media Soc. 2014, 18, 353-372. [CrossRef]

111. Schrøder, K. Audiences are inherently cross-media: Audience studies and the cross-media challenge. Commun. Manag. Q. 2011, 18, 5-27.

112. Katz, E.; Gurevitch, M.; Haas, H. On the use of the mass media for important things. Am. Sociol. Rev. 1973, 38, 164. [CrossRef]

113. Bertaux, D. Oral History Approaches to an International Social Movement. In Comparative Methodology: Theory and Practice in International Social Research; Øyen, E., Ed.; Sage: London, UK, 1990; pp. 151-171, ISBN 978-0803983267.

(C) 2018 by the author. Licensee MDPI, Basel, Switzerland. This article is an open access article distributed under the terms and conditions of the Creative Commons Attribution (CC BY) license (http:/ / creativecommons.org/licenses/by/4.0/). 